Check for updates

Cite this: RSC Adv., 2020, 10, 8309

Received 23rd December 2019

Accepted 10th February 2020

DOI: $10.1039 / \mathrm{dOra01072c}$

rsc.li/rsc-advances

\section{Electrochemical preparation system for unique mesoporous hemisphere gold nanoparticles using block copolymer micelles $\dagger$}

\author{
Hyunsoo Lim, (D) $\ddagger^{a}$ Tomota Nagaura, $\dot{t}^{\mathrm{a}}$ Minjun Kim, (D) ${ }^{a}$ Kenya Kani, ${ }^{a}$ \\ Jeonghun Kim, (iD abc Yoshio Bando, (iD) def Saad M. Alshehri, ${ }^{9}$ Tansir Ahamad, ${ }^{9}$

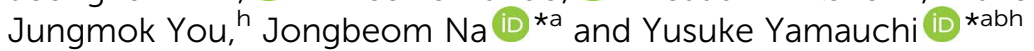

Gold nanoparticles (AuNPs) are widely used in various applications, such as biological delivery, catalysis, and others. In this report, we present a novel synthetic method to prepare mesoporous hemisphere gold nanoparticles (MHAuNPs) via electrochemical reduction reaction with the aid of polymeric micelle assembly as a pore-directing agent.
Gold $(\mathrm{Au})$ is one of the most stable and versatile elements utilized in various fields, including catalysis, optics, and industrial purposes. Consequently, various shapes and sizes of AuNPs have been intensively studied to improve the performance of Au in different applications..$^{1-6}$ Previously, nanoporous or dendritic metal nanostructures, including $\mathrm{Au}$ nanostructures, have been synthesized by employing different reagents and conditions such as SH-terminated amphiphilic surfactant, ${ }^{7} \mathrm{pH}$ controlling, ${ }^{8}$ and hard-templates., ${ }^{9,10}$ The reported porous and dendritic Au nanostructures possess high surface areas and rich active sites, which in turn lead to highly enhanced catalytic activities.

Recently, a soft-template method using self-assembled micelles or lyotropic liquid crystals as pore-directing agents has allowed the successful synthesis of mesoporous

\footnotetext{
${ }^{a}$ Australian Institute for Bioengineering and Nanotechnology (AIBN) and School of Chemical Engineering, The University of Queensland, Brisbane, QLD, 4072, Australia.E-mail: y.yamauchi@uq.edu.au

${ }^{b}$ Key Laboratory of Eco-chemical Engineering, College of Chemistry and Molecular Engineering, Qingdao University of Science and Technology, Qingdao 266042, China 'Department of Chemistry, Kookmin University, 77 Jeongneung-ro, Seongbuk-gu, Seoul, 02707, Republic of Korea

${ }^{d}$ International Center for Materials Nanoarchitechtonics (MANA), National Institute for Materials Science (NIMS), 1-1 Namiki, Tsukuba, Ibaraki 305-0044, Japan

'Institute of Molecular Plus, Tianjin University, No. 92 Weijin Road, Nankai District, Tianjin, 300072, P. R. China

${ }^{f}$ Australian Institute of Innovative Materials (AIIM), The University of Wollongong, Squires Way, North Wollongong, NSW 2500, Australia

${ }^{g}$ Department of Chemistry, College of Science, King Saud University, Riyadh 11451, Saudi Arabia

${ }^{h}$ Department of Plant \& Environmental New Resources, Kyung Hee University, 1732 Deogyeong-daero, Giheung-gu, Yongin-si, Gyeonggi-do 446-701, South Korea

$\dagger$ Electronic supplementary information (ESI) available: SEM and TEM images of MHAuNPs, chronoamperometry curves for Au deposition, SERS, and Tyndall effect of colloidal HMAuNPs suspension. See DOI: 10.1039/d0ra01072c

$\ddagger$ These authors contributed equally.
}

nanoparticles ${ }^{11-13}$ and films ${ }^{14-17}$ with different metal compositions. The metals with mesoporous structures demonstrate superior catalytic activity per weight or surface area over their nonporous bulk forms. Previously, our group reported a severalfold increase in the catalytic activity of mesoporous metals in reactions such as the methanol oxidation reaction (MOR), ${ }^{14,15}$ ethanol oxidation reaction (EOR),,$^{13,15-17}$ and nitric oxide reduction $^{12}$ as compared to their bulk nanoparticles and films. Such improvement in the catalytic activity of mesoporous structures is mainly attributed to their significantly larger surface areas, more exposed catalytically active sites, and increased durability against aggregation.

Interestingly, nanoporous or mesoporous Au structures had been successfully synthesized by using a dealloying method ${ }^{18}$ and a hard templating method. ${ }^{9}$ Such methods, however, are a little complicated, and pore-directing templates often remain within the pores, thus leading to severe contamination. Using a thiol group is an alternative way to synthesize mesoporous $\mathrm{Au}$ nanospheres. ${ }^{7}$ A significant drawback of using a thiol group, however, is its strong chemical bonding with $\mathrm{Au}$, thus becoming unable to be removed. The synthesis of mesoporous structures using self-assembled polymeric micelles as soft-templates, on the other hand, is a more facile method with fewer synthetic steps, and it is also known to be free of contaminations within the pores. Although a soft-templating method using polymeric micelles has been utilized for the preparation of mesoporous $\mathrm{Au}$ and Au-based alloy films towards surface-enhanced Raman scattering (SERS) signals, ${ }^{19}$ glucose sensing, ${ }^{20,21}$ and MOR, ${ }^{22}$ the obtained morphologies have been limited to only films.

Despite such apparent benefits arising from mesoporous structures and their synthesis using soft-templates, the synthesis of mesoporous AuNPs using soft-templates has not been achieved yet. It is mainly due to the physical and chemical properties of $\mathrm{Au}$ which make it extremely hard to form 
mesoporous structures. Herein, we adopt an electrochemical approach and the soft-template method to synthesize MHAuNPs successfully. As discussed above, we expect MHAuNPs to be highly efficient in various applications in medical diagnosis, ${ }^{23}$ optical sensing, ${ }^{24}$ etc.

In this report, MHAuNPs with different shapes and sizes are for the first time reported by changing various electrochemical deposition conditions such as applied potentials between electrodes and deposition times. Scheme 1 shows the schematic illustrations of the entire process of precursor preparation (Scheme 1a) and the MHAuNPs fabrication process (Scheme 1b), including the deposition and the detachment of the nanoparticles. The characterization methods implemented in this paper are mentioned in ESI. $\dagger$

In a typical experiment, a p-doped silicon ( $\mathrm{Si}$ ) wafer was cleaned by using acetone, isopropyl alcohol, and deionized water (DIW) with sonication for 5 minutes, followed by nitrogen $\left(\mathrm{N}_{2}\right)$ gas blowing to dry the Si wafer. After the wet cleaning process, the $\mathrm{Si}$ surface was treated by oxygen $\left(\mathrm{O}_{2}\right)$ plasma for 5 minutes (Oxford Instruments PlasmaPro 80 Reactive Ion Etcher) to remove residual organic impurities. Then, $10 \mathrm{~nm}$ of titanium (Ti) layer and $100 \mathrm{~nm}$ of Au layer were deposited sequentially by electron beam evaporation (Temescal FC-2000 e-beam evaporator) at $10^{-6}$ torr. Commercially available Au etchant (Sigma-Aldrich) was used to etch the $\mathrm{Au}$ film to expose the Ti area (the left image in Scheme $1 \mathrm{~b}$ ). During etching, about 20 percent of Au area was left to be connected to the electrochemical work station, as drawn in Scheme $1 \mathrm{~b}$. In preparation of the $\mathrm{Au}$ precursor solution, $5 \mathrm{mg}$ of poly(styrene)-block-poly(ethylene oxide) (PS$b$-PEO, the number of average molecular weight $\left(M_{\mathrm{w}}\right)$ for each block is 18000 for PS and 7500 for PEO, respectively) was mixed in $1.5 \mathrm{ml}$ of tetrahydrofuran (THF) followed by stirring at $300 \mathrm{rpm}$ for 8 hours. Then, $0.75 \mathrm{ml}$ of ethanol, $0.5 \mathrm{ml}$ of $\mathrm{HAuCl}_{4}$ aqueous solution ( $40 \mathrm{mM}$ ), and $1.25 \mathrm{ml}$ of DIW were added sequentially. The solution was stirred for another 30 minutes at $200 \mathrm{rpm}$. The existing block copolymer micelles can be confirmed by TEM observation, and the average diameter is $25 \mathrm{~nm}$, as shown in Fig. S1.† For the electrochemical deposition, an electrochemical workstation $(\mathrm{CH}$ Instruments Inc. 660e) with three electrode system was used to deposit MHAuNPs on the Ti/Si substrate. After the

(a)
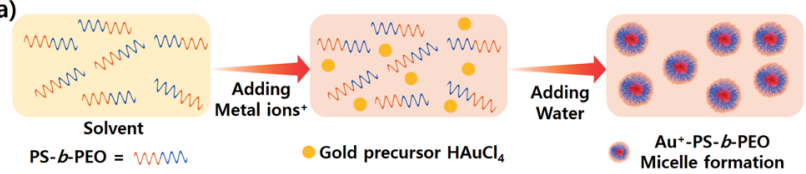

(b)

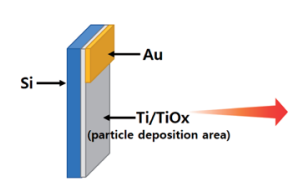

Substrate preparation

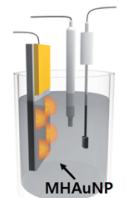

Electrochemical deposition

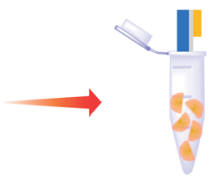

Sonication

Scheme 1 (a) The process of Au precursor solution preparation and (b) fabricating MHAuNPs by electrochemical reduction. deposition, the particles were carefully washed by chloroform, followed by a rinse using DIW to remove the residual micelles completely. To detach and collect MHAuNPs from the $\mathrm{Ti} / \mathrm{Si}$ substrate, the substrate was soaked in ethanol and strongly sonicated for a few minutes (Scheme 1b).

Fig. $\mathrm{S} 2 \uparrow$ shows the details of the growth mechanism of MHAuNPs by different deposition times. At the initial stage (Fig. S2a $\dagger$ ), small nanoparticles are generated by reducing $\mathrm{Au}$ ions in the precursor solution throughout the substrate. Then, the seed starts growing and forming MHAuNPs as the deposition time increases (Fig. S2b-e $\dagger$ ). This similar growth mechanism is the same as the previous report. ${ }^{19}$ The high-angle annular detector dark-field scanning transmission electron microscopy (HAADF-STEM) image (Fig. S2f $\dagger$ ) shows the mesopores inside the MHAuNPs are homogeneously generated. Asobtained MHAuNPs consist of a pure Au element without any impurities, as shown in Fig. S3. $\dagger$

Fig. 1 and $\mathrm{S} 4 \dagger$ show scanning electron microscope (SEM) images of MHAuNPs deposited at different voltages from $-0.2 \mathrm{~V}$ to $-0.9 \mathrm{~V}$ vs. $\mathrm{Ag} / \mathrm{AgCl}$ at high magnification and low
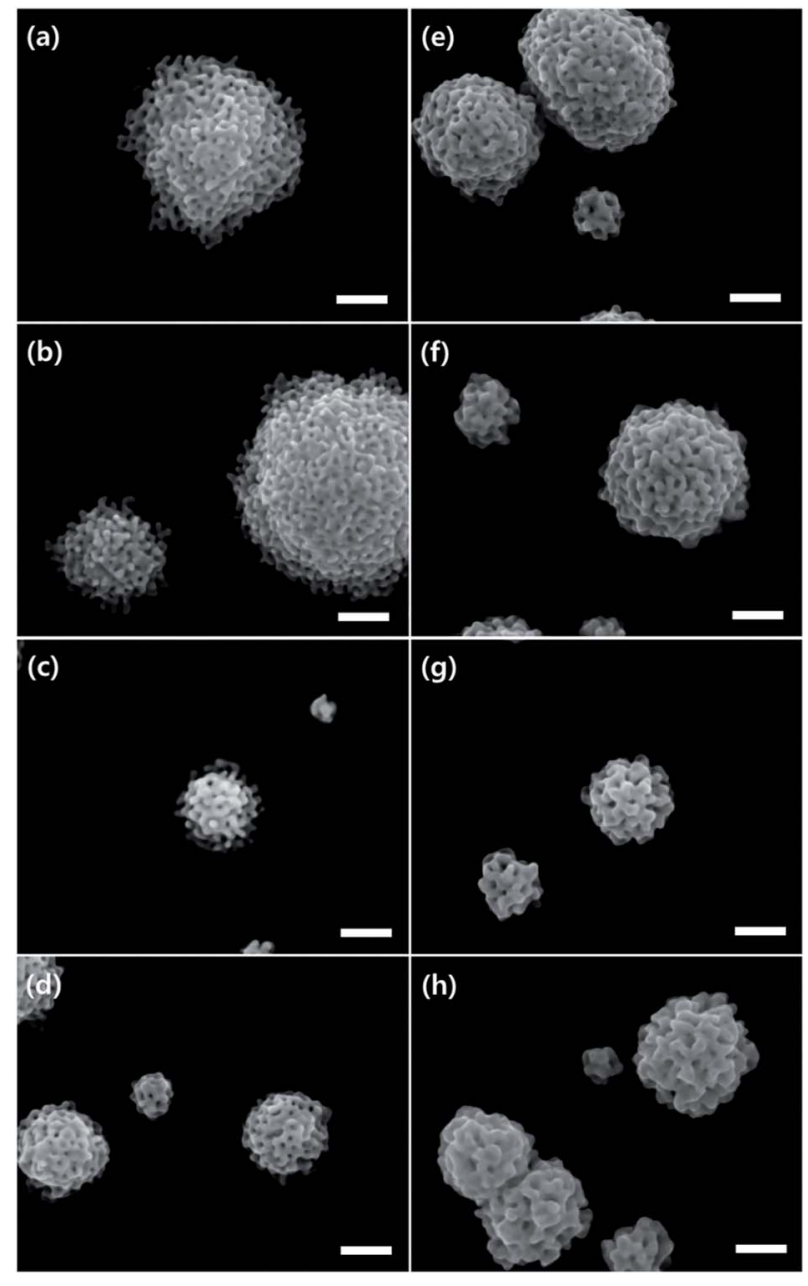

Fig. 1 The SEM images of MHAuNPs electrochemically deposited at (a) $-0.2 \mathrm{~V}$, (b) $-0.3 \mathrm{~V}$, (c) $-0.4 \mathrm{~V}$, (d) $-0.5 \mathrm{~V}$, (e) $-0.6 \mathrm{~V}$, (f) $-0.7 \mathrm{~V}$, (g) $-0.8 \mathrm{~V}$, and $(\mathrm{h})-0.9 \mathrm{~V}$ for $500 \mathrm{~s}$. The scale bars indicate $200 \mathrm{~nm}$. 
magnification, respectively. Different deposition voltages lead to significant changes in the particle sizes but slight differences in the particle shapes. The size distributions of MHAuNPs and the plots of the average diameters of MHAuNPs by different deposition voltages are described in Fig. 2. The distribution graphs show the large sizes of particles, such as more than $1 \mu \mathrm{m}$ in diameter, when the high voltage $(-0.2 \mathrm{~V} v s$. $\mathrm{Ag} / \mathrm{AgCl})$ is applied (Fig. 2a). The distribution becomes narrower upon the lower applied voltage. The average diameter-applied voltage plots in Fig. 2b show that the average particle size decreases from around $1.1 \mu \mathrm{m}$ at $-0.2 \mathrm{~V}$ to about $300 \mathrm{~nm}$ at $-0.9 \mathrm{~V}$. Thus when the lower deposition voltages are applied (i.e., the deposition rate is higher) (Fig. 1g-h), the smaller particles with a higher degree of size uniformity are obtained. The opposite trend is observed at higher deposition voltages (i.e., the
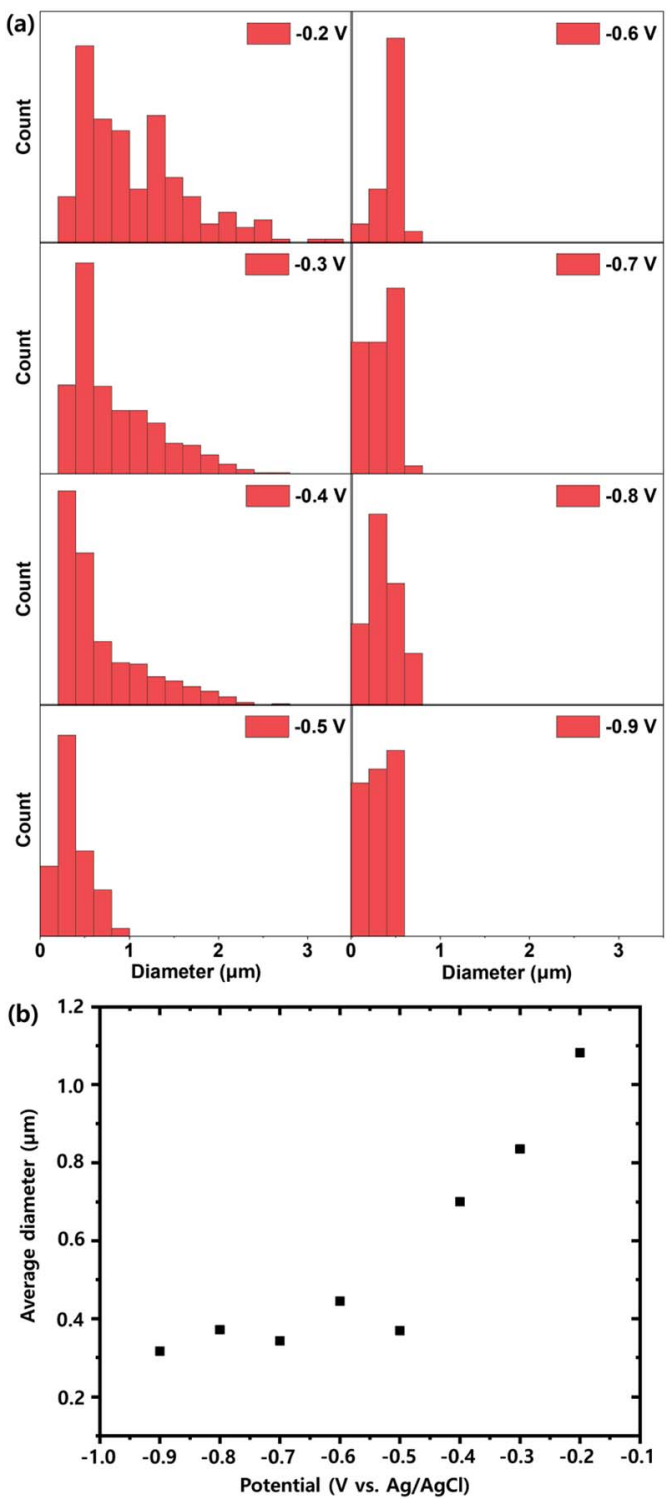

Fig. 2 (a) Size distributions of MHAuNPs generated by different voltages and (b) the average diameter-the applied voltage plots. deposition rate is lower) (Fig. 1a and b), at which the particles become larger and their size uniformity decreases. This trend is because the higher voltage allows only a limited number of seed particles to be deposited on the Ti/Si substrate, and each seed individually grows with no additional seed formation. Whereas the lower voltage can allow a higher number of seeds, leading to a uniform supply of electrons from the working Ti/Si electrode (Fig. S5†). In addition, the lower deposition voltages make the particle shape more hemispherical in Fig. 1f-h.

Fig. 3 shows the SEM images of MHAuNPs deposited at $-0.2 \mathrm{~V}$ and for different deposition times from $250 \mathrm{~s}$ to $1000 \mathrm{~s}$. Although longer deposition time does not change the number of MHAuNPs, it leads to the growth of MHAuNPs in lateral and vertical directions. Although the MHAuNPs grow more than about two or three times larger at long deposition time, the mesoporous formation does not seem to be changed, as shown in insets in Fig. 3. This point indicates that the deposition time is not the main factor affecting the formation of mesoporous structures as well as the number of particles (seeds), but it affects the sizes of particles.

In this report, $10 \mathrm{~nm}$ Ti layer on Si wafer plays an important key role in the formation of MHAuNPs, as previously mentioned in the experimental procedure. The use of the Ti substrate with low conductivity ( $c a .2 .38 \times 10^{6} \mathrm{~S} \mathrm{~m}^{-1}$ ), which is about only $5.8 \%$ in comparison with that of $\mathrm{Au}\left(\mathrm{ca} .4 .10 \times 10^{7} \mathrm{~S} \mathrm{~m}^{-1}\right)$, is not common in the electrochemical plating research field. ${ }^{25-30}$ Most of the papers on mesoporous metal structures synthesized by electrochemical deposition have utilized Au or Pt substrates due to its chemical stability and high electrical conductivity. ${ }^{\mathbf{1 4 - 1 7}}$ Fig. S6 $\dagger$ shows the amperometry $(i-t)$ curves during the deposition of MHAuNPs (black dots) on a Ti/Si substrate and mesoporous gold films (red dots) on an Au substrate at the same deposition condition. As shown in Fig. S6, $\dagger$ around 1/7 times less current flows on the $\mathrm{Ti} / \mathrm{Si}$ substrate throughout the deposition time. This low current density on the Ti/Si substrate is one of the factors for fabricating MHAuNPs. Low current density causes the formation of a few particles (i.e., seeds) at the initial stage of the deposition and leads to seed growth in a few places, as explained in Fig. S2. $\dagger$ Furthermore, the use of $\mathrm{Ti} / \mathrm{Si}$ substrates affects the bottom parts of MHAuNPs to become an arch shape. Only edges of MHAuNPs attach onto the $\mathrm{Ti} / \mathrm{Si}$ substrates, as shown in Fig. 4. This attachment is because the interaction between the deposited MHAuNPs and the Ti substrate surface (probably, the Ti surface can be partially oxidized, forming $\mathrm{TiO}_{x}$ ) is very weak. Therefore, the deposited MHAuNPs can be easily detached from the Ti/Si substrates by sonicating the substrates in solvents (Scheme 1b). The collected MHAuNPs in a solvent are obtained as colloidal particles as shown in Fig. S7. $\uparrow$ Such interesting hemispherical mesoporous nanoparticles have advantages to electrocatalytic activities in comparison to spherical mesoporous metals. ${ }^{31}$ The method using a Ti/Si substrate as a working electrode can be repeatedly implemented with one substrate and without change of the precursor solution, thus it can be effective for mass production in the future.

Finally, surface-enhanced Raman scattering (SERS) effects on MHAuNPs were investigated by using an adsorbate called 

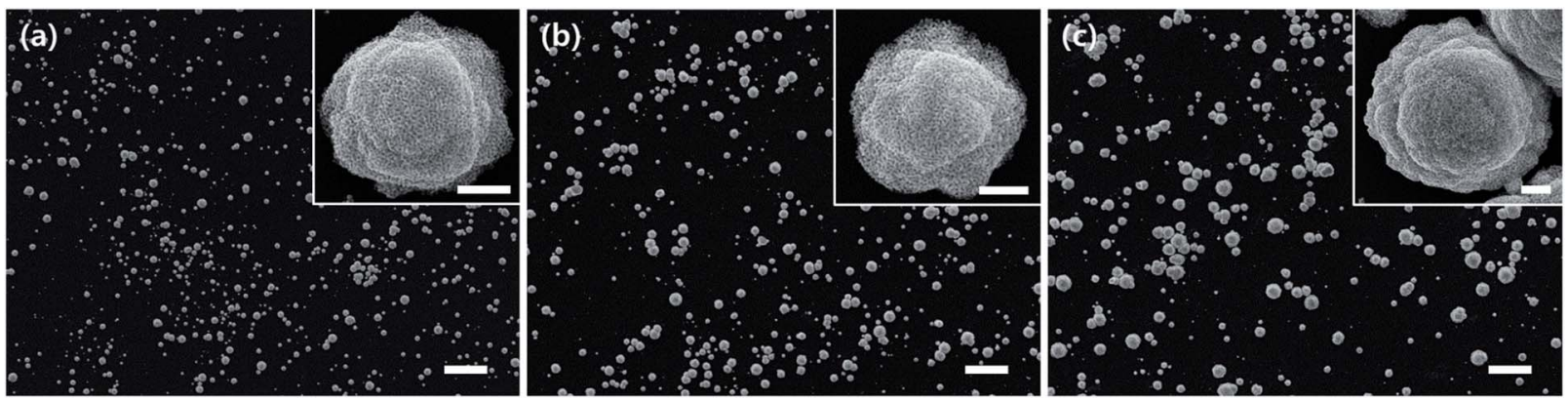

Fig. 3 The SEM images of MHAuNPs deposited at $-0.2 \mathrm{~V}$ (vs. Ag/AgCl) for (a) $250 \mathrm{~s}$, (b) $500 \mathrm{~s}$, and (c) $1000 \mathrm{~s}$. The scale bars indicate $10 \mu \mathrm{m}$. The insets in each figure are magnified SEM images of each condition (The scale bars in insets indicate $500 \mathrm{~nm}$ ).

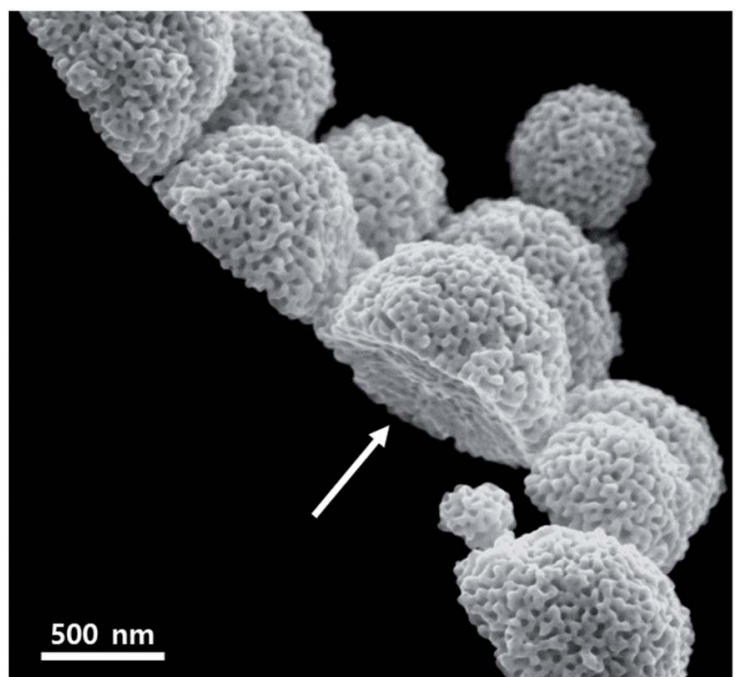

Fig. 4 The SEM image of MHAuNPs deposited at $-0.6 \mathrm{~V}$. The arrow shows that the bottom of the MHAuNPs is an arch.

rhodamine 6G (R6G), as shown in Fig. S8. $\dagger$ The resulting MHAuNPs at all conditions $(-0.3 \mathrm{~V},-0.6 \mathrm{~V}$, and $-0.9 \mathrm{~V})$ show substantially strong SERS intensity (Fig. S8a†), while Ti/Si and Si substrates without MHAuNPs show noise level of intensity. To further investigate enhancement factor $(\mathrm{EF})$ and limit of detection (LoD), various concentrations of R6G with MHAuNPs fabricated at $-0.9 \mathrm{~V}$ were used for the SERS studies (Fig. S8b†). The main peak of SERS is $1363 \mathrm{~cm}^{-1}$, and it disappears from less than $10^{-6} \mathrm{M}$ concentration, while the $1183 \mathrm{~cm}^{-1}$ peak still exists at $10^{-8} \mathrm{M}$ (Fig. S8c $\dagger$ ). The maximum EFs at $1363 \mathrm{~cm}^{-1}$ $\left(10^{-6} \mathrm{M}\right)$ and $1183 \mathrm{~cm}^{-1}\left(10^{-8} \mathrm{M}\right)$ are $1.5 \times 10^{4}$ and $3.1 \times 10^{6}$, respectively (Fig. S8d $\dagger$ ). Transmission electron microscope (TEM) images in Fig. S9† show the detailed particle structures and the electron diffraction (ED) pattern confirmed the crystal structure is the face-center cubic (FCC) structure. The sharp surface structures and the pores on MHAuNPs provide abundant hot spots that have been reported as the origin that enhances SERS intensity owing to the plasmon resonances. ${ }^{19,32}$ Besides, the high density of small-sized MHAuNPs (Fig. S5 and S10†) boosted higher SERS intensity.
In conclusion, we have synthesized MHAuNPs by using $10 \mathrm{~nm}$ Ti-coated Si substrates as a working electrode on a Si wafer and electrochemical deposition using self-assembled polymeric micelles as pore-directing agents. The low current generates $\mathrm{Au}$ seeds at only a few places, and it acts as the points that MHAuNPs start growing. The particle shapes and sizes can be controlled by changed applied voltages and deposition times. The lower voltages make small particles and the great hemispherical AuNPs with mesoporous architecture. The long-time deposition does not affect any mesoporous formation, but the particle shape and size. Besides, the low affinity between $\mathrm{Au}$ and Ti (probably, oxidized layer) results in the arch on the bottom of MHAuNPs, which helps the particles detached from the substrates easily. These results indicate that different thicknesses and compositions of working electrodes can provide different metal deposition phenomena, which can bring out unique shaped particles with mesoporous architectures in the future.

\section{Conflicts of interest}

There are no conflicts to declare.

\section{Acknowledgements}

This work was supported by Australian Research Council (ARC) Future Fellowship (FT150100479). This work was performed in part at the Queensland node of the Australian National Fabrication Facility (ANFF), a company established under the National Collaborative Research Infrastructure Strategy to provide nano and microfabrication facilities for Australia's researchers. The authors also thanks to Researchers Supporting Project number (RSP-2019/6), King Saud University, Riyadh, Saudi Arabia. The authors acknowledge the facilities, and the scientific and technical assistance, of the Australian Microscopy \& Microanalysis Research Facility at the Centre for Microscopy and Microanalysis, The University of Queensland.

\section{Notes and references}

1 J. Turkevich, P. C. Stevenson and J. Hillier, Discuss. Faraday Soc., 1951, 11, 55.

2 G. Frens, Nat. Phys. Sci., 1973, 241, 20. 
3 R. Sardar and J. S. Shumaker-Parry, J. Am. Chem. Soc., 2011, 133, 8179.

4 I. Hussain, S. Graham, Z. Wang, B. Tan, D. C. Sherrington, S. P. Rannard, A. I. Cooper and M. Brust, J. Am. Chem. Soc., 2005, 127, 16398.

5 N. R. Jana, L. Gearheart and C. J. Murphy, Langmuir, 2001, 17, 6782.

6 M. Grzelczak, J. Pérez-Juste, P. Mulvaney and L. M. LizMarzán, Chem. Soc. Rev., 2008, 37, 1783.

7 H. Lv, D. Xu, J. Henzie, J. Feng, A. Lopes, Y. Yamauchi and B. Liu, Chem. Sci., 2019, 10, 6423.

8 G. W. Qin, J. Liu, T. Balaji, X. Xu, H. Matsunaga, Y. Hakuta, L. Zuo and P. Raveendran, J. Phys. Chem. C, 2008, 112, 10352.

9 J. Fang, L. Zhang, J. Li, L. Lu, C. Ma, S. Cheng, Z. Li, Q. Xiong and H. You, Nat. Commun., 2018, 9, 521.

10 H. Wang, H. Y. Jeong, M. Imura, L. Wang, L. Radhakrishnan, N. Fujita, T. Castle, O. Terasaki and Y. Yamauchi, J. Am. Chem. Soc., 2011, 133, 14526.

11 G. S. Attard, C. G. Göltner, J. M. Corker, S. Henke and R. H. Templer, Angew. Chem., Int. Ed. Engl., 1997, 36, 1315.

12 B. Jiang, C. Li, Ö. Dag, H. Abe, T. Takei, T. Imai, M. S. A. Hossain, M. T. Islam, K. Wood, J. Henzie and Y. Yamauchi, Nat. Commun., 2017, 8, 15581.

13 C. Li, M. Iqbal, B. Jiang, Z. Wang, J. Kim, A. K. Nanjundan, A. E. Whitten, K. Wood and Y. Yamauchi, Chem. Sci., 2019, 10, 4054.

14 H. Wang, L. Wang, T. Sato, Y. Sakamoto, S. Tominaka, K. Miyasaka, N. Miyamoto, Y. Nemoto, O. Terasaki and Y. Yamauchi, Chem. Mater., 2012, 24, 1591.

15 B. Jiang, C. Li, H. Qian, M. S. A. Hossain, V. Malgras and Y. Yamauchi, Angew. Chem., Int. Ed., 2017, 56, 7836.

16 M. Iqbal, C. Li, K. Wood, B. Jiang, T. Takei, Ö. Dag, D. Baba, A. S. Nugraha, T. Asahi, A. E. Whitten, M. S. A. Hossain, V. Malgras and Y. Yusuke, Chem. Mater., 2017, 29, 6405.

17 M. Iqbal, J. Kim, B. Yuliarto, B. Jiang, C. Li, Ö. Dag, V. Malgras and Y. Yamauchi, ACS Appl. Mater. Interfaces, 2018, 10, 40623.
18 Y. Ding and J. Erlebacher, J. Am. Chem. Soc., 2003, 125, 7772. 19 C. Li, Ö. Dag, T. D. Dao, T. Nagao, Y. Sakamoto, T. Kimura, O. Terasaki and Y. Yamauchi, Nat. Commun., 2015, 6, 6608. 20 A. S. Nugraha, V. Malgras, M. Iqbal, B. Jiang, C. Li, Y. Bando, A. Alshehri, J. Kim, Y. Yamauchi and T. Asahi, ACS Appl. Mater. Interfaces, 2018, 10, 23783.

21 A. S. Nugraha, C. Li, J. Bo, M. Iqbal, S. M. Alshehri, T. Ahamad, V. Malgras, Y. Yamauchi and T. Asahi, ChemElectroChem, 2017, 4, 2571.

22 C. Li, B. Jiang, H. Chen, M. Imura, L. Sang, V. Malgras, Y. Bando, T. Ahamad, S. M. Alshehri, S. Tominaka and Y. Yamauchi, Nano Res., 2016, 9, 1752.

23 G. Peng, U. Tisch, O. Adams, M. Hakim, N. Shehada, Y. Y. Broza, S. Billan, R. Abdah-Bortnyak, A. Kuten and H. Haick, Nat. Nanotechnol., 2009, 4, 669.

24 G. Kwon, J. Kim, D. Kim, Y. Ko, Y. Yamauchi and J. You, Cellulose, 2019, 26, 4935.

25 C. Li, M. Iqbal, J. Lin, X. Luo, B. Jiang, V. Malgras, K. C. W. Wu, J. Kim and Y. Yamauchi, Acc. Chem. Res., 2018, 51, 1764.

26 H. Lim, J. Kim, K. Kani, M. K. Masud, H. Park, M. Kim, S. M. Alsheri, T. Ahamad, N. Alhokbany, J. Na, V. Malgras, Y. Bando and Y. Yamauchi, Small, 2019, 1902934.

27 M. S. El-Deab and T. Ohsaka, Electrochem. Commun., 2002, 4, 288.

28 M. Nishizawa, T. Sunagawa and H. Yoneyama, Langmuir, 1997, 13, 5215.

29 M. E. Martins, R. C. Salvarezza and A. J. Arvia, Electrochim. Acta, 1996, 41, 2441.

30 S. L. Vot, L. Roué and D. Bélanger, Electrochim. Acta, 2012, 59, 49.

31 H. Lv, D. Xu, L. Sun, J. Henzie, A. Lopes, Q. Gu, Y. Yamauchi and B. Liu, Nano Lett., 2019, 19, 3379.

32 E. Hao and G. C. Schatz, J. Chem. Phys., 2004, 120, 357. 